\title{
Risk of Nondherence to Diabetes Medications Among Medicare Advantage Enrollees: Development of a Validated Risk Prediction Tool
}

\author{
Shivani K. Mhatre, PhD; Omar Serna, PharmD; Shubhada Sansgiry, PhD;
}

Marc L. Fleming, PhD, MPH, RPh; E. James Essien, MD, DrPH; and Sujit S. Sansgiry, PhD

\begin{abstract}
BACKGROUND: Low adherence to oral antidiabetic drugs (OADs) in the Medicare population can greatly reduce Centers for Medicare \& Medicaid Services (CMS) star ratings for managed care organizations (MCOs).

OBJECTIVE: To develop and validate a risk assessment tool (Prescription Medication Adherence Prediction Tool for Diabetes Medications [RxAPT-D]) to predict nonadherence to OADs using Medicare claims data.

METHODS: In this retrospective observational study, claims data for members enrolled in a Medicare Advantage Prescription Drug (MA-PD) program in Houston, Texas, were used. Data from 2012 (baseline period) were used to identify key variables to predict adherence in $\mathbf{2 0 1 3}$ (follow-up period). Members aged 65 years and older with a diabetes diagnosis, at least 1 prescription for OADs (biguanides, sulfonylureas, thiazolidinediones, dipeptidyl peptidase-4 inhibitors, or meglitinides), and continuously enrolled for both years were included in the study. Patients with insulin prescriptions were excluded from the cohort. The study outcome, nonadherence in 2013, was defined as proportion of days covered (PDC) $<80 \%$. Multivariable logistic models using 200 bootstrap replications (with replacement) identified factors associated with nonadherence. The final model was tested for discrimination and calibration statistics and internally validated using 10 -fold cross-validation. Using weighted beta coefficients of the predictors, the RxAPT-D was created to stratify nonadherence risk and was tested for sensitivity, specificity, positive prediction value, and negative prediction value. The predictive ability of the tool was compared with that of past PDC values using net reclassification improvement (NRI) and integrated discrimination improvement (IDI) indices.
\end{abstract}

RESULTS: Data from 7,028 MA-PD members were used for tool development. Seven predictors (age, total OAD refills, total OAD classes filled, days supply of last filled OAD, pill burden, coverage of last filled OAD, and past adherence) statistically significant in $\geq 50 \%$ of the bootstrapped samples were identified from the logistic models. The final model demonstrated good discrimination (c-statistics $=0.75$ ) and calibration (Hosmer-Lemeshow goodness-of-fit $P>0.05$ ) statistics, with good internal validity (area under the curve $=0.73$ ). The RxAPT-D demonstrated adequate sensitivity statistics: sensitivity $=0.73$, specificity $=0.63$, positive prediction value $=0.74$, and negative prediction value $=0.62$. Compared with use of past adherence measures, the RxAPT-D had higher prediction ability, relative $I D I=2.09$, and user defined $\mathrm{NRI}=0.16$ with $24 \%$ events correctly reclassified.

CONCLUSIONS: The RxAPT is an effective tool to identify patients who are likely to become nonadherent to OADs in the follow-up year. Pharmacists in MCOs can use this tool to identify patients expected to be nonadherent to OADs and develop targeted intervention programs to assist in improving MCO CMS star ratings.

J Manag Care Spec Pharm. 2016;22(11):1293-301

Copyright $\odot 2016$, Academy of Managed Care Pharmacy. All rights reserved.

\section{What is already known about this subject}

Adherence to oral diabetes medications is low among the elderly Medicare population.

Many variables obtained from patient claims data are associated with nonadherence, including demographic, medication-related, and disease factors; cost factors that can be either related to cost of medications or income; and socioeconomic status.

\section{What this study adds}

A nonadherence prediction tool for oral antidiabetic drugs users was developed using claims data routinely collected by managed care organizations.

This tool, developed using a weighted combination of significant predictors, had higher sensitivity to identify nonadherent patients in the subsequent year, compared with use of a patient's adherence history as an adherence indicator.

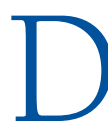
iabetes imposes a substantial burden on the economy of the United States - the total estimated cost of diagnosed diabetes in 2012 was $\$ 245$ billion. ${ }^{1}$ Approximately $59 \%$ of all health care expenditures attributed to diabetes are for health resources that are used by the elderly population, much of which is borne by the Medicare program. ${ }^{1}$ A higher proportion of expenditures related to diabetes complications suggests that interventions to delay or prevent the development of complications and comorbidities in elderly Americans diagnosed with diabetes may be most effective in stemming the growing economic burden of diabetes. ${ }^{2}$ The American Diabetes Association guidelines and the European Association for the Study of Diabetes recommend use of oral antidiabetic drugs (OADs) as first-line therapy in type 2 diabetes patients. ${ }^{3}$ However, adherence is considerably low among Medicare beneficiaries. The Centers for Medicare \& Medicaid Services (CMS) reported adherence to diabetes medications among only $77 \%$ patients in 2013. ${ }^{4}$ A previous study of diabetes patients demonstrated association between decrease in medication adherence and increase in medical cost. ${ }^{5}$ Other studies have reported an 8.3\%-28.9\% decrease in annual costs with every $10 \%$ increase in adherence among Medicare diabetes patients. ${ }^{6,7}$

As part of an effort to increase medication adherence, CMS added medication adherence measures to the star ratings 


\section{FIGURE 1 Patient Attrition Flowchart}

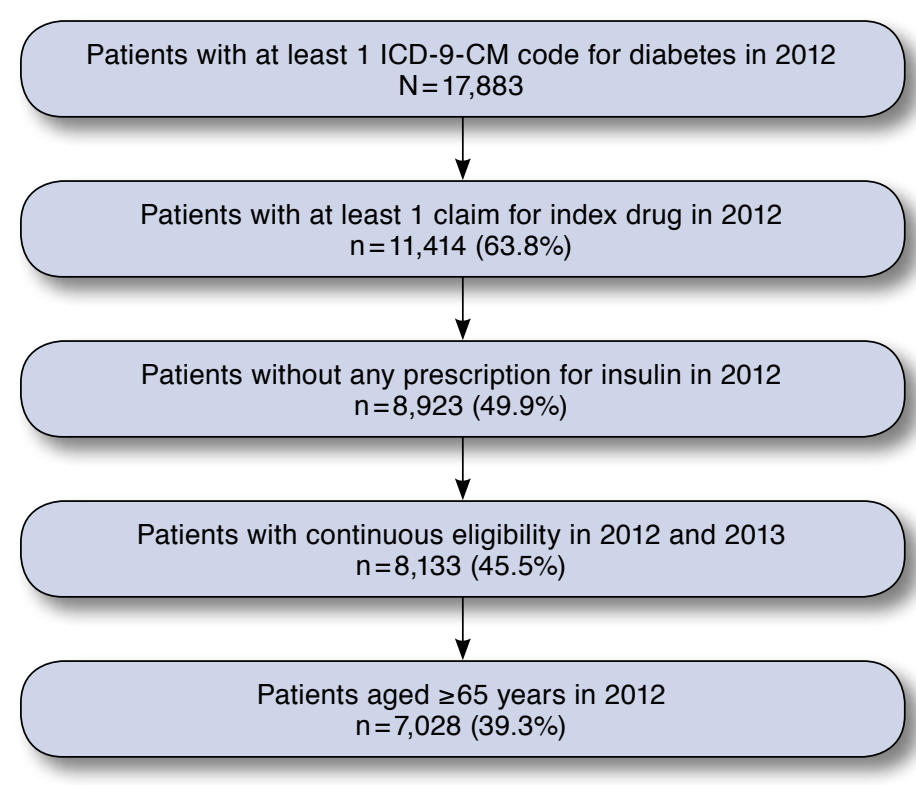

ICD-9-CM= International Classification of Diseases, Ninth Revision, Clinical Modification.

program in 2012, with a high scoring weight of $3 .{ }^{8}$ The Medicare programs are rated for adherence to diabetes medications by calculating the percentage of plan members with prescriptions for diabetes medications who fill their prescriptions often enough to cover $80 \%$ or more of the time they are supposed to be taking the medication. High proportions of adherent patients lead to higher scores on the measure, which contribute to achieving higher star ratings. Higher star ratings can lead to significant economic gains for the Medicare programs. For a Medicare Advantage plan with 1 million members, moving from a 3-star to a 5-star rating would boost revenue by approximately $\$ 200$ million. $^{9}$ Beginning in 2015 , only plans scoring 4 stars and above are eligible for quality bonus payments. ${ }^{9}$ The expected difference in payments compared with a 3-star plan is about $16 \%$ per member per month, which can have a significant effect on large health plans.

In this study, we developed a risk prediction tool called Prescription Medication Adherence Prediction Tool for Diabetes Medications (RxAPT-D) to identify risk for nonadherence to OADs. Claims data have been widely cited in medical literature for health risk assessment purposes, such as developing risk adjustment models or to predict future costs, inappropriate use, or risk of a disease/comorbidity. ${ }^{10-12}$ There is no algorithm, however, to predict risk of nonadherence to medications in general and OADs in particular. There are many studies that identify predictors of nonadherence to OADs and few that predict nonadherence specifically among the Medicare population. ${ }^{6,13}$ However, to use the information for risk prediction, a validated algorithm would be required, which this study aimed to achieve. The algorithm developed for this study included variables that have been significantly associated with nonadherence to oral medication in the literature. Proactive identification of patients at risk for future nonadherence can provide managed care organizations (MCOs) with a selective cost-effective approach to implement adherence intervention programs.

\section{Methods}

\section{Study Design and Data Source}

A retrospective study was conducted using the CignaHealthSpring administrative claims data for patients residing in Southeast Texas and enrolled in the Medicare Advantage Prescription Drug (MA-PD) program from 2012-2013.

Five types of data files were used: (1) membership files that contained patient demographic information, (2) member summary files that contained enrollment and other information on a per-month-per-patient basis, (3) pharmacy claims files that contained prescription medication information, (4) professional files that contained information on physician visits, and (5) institutional files that contained information on hospitalizations. Data from 2012 were used to identify the predictor variables to develop the model to predict nonadherence in 2013. Following model development and validation, weighted beta coefficients from the final prediction model were used to develop the RxAPT-D to stratify nonadherence risk.

\section{Study Population}

This study included diabetes patients (International Classification of Diseases, Ninth Revision, Clinical Modification code 250.xx) with at least 1 prescription for oral diabetes medication from any of the 5 OAD classes (biguanides, sulphonyureas, thiazolidinedione, dipeptidyl peptidase-4 inhibitors, or meglitinides); continuous enrollment eligibility over 2 years (2012 and 2013) without any gap; and aged $\geq 65$ years (Figure 1). If any of the included patients had at least 1 claim for insulin, they were excluded from the study. All the inclusion and exclusion criteria were applied in the baseline year. The sample selection criteria was according to 2015 CMS star rating guidelines for diabetes patients on specific OADs and enrolled in the MA-PD program. ${ }^{4}$

\section{Measurement and Operational Definition of Variables}

A literature search identified variables with either a causal or a correlational relationship with adherence to oral medications. All variables were considered categorical rather than continuous.

The dependent variable was adherence to OADs measured during the follow-up year and defined as conforming to provider recommendations. ${ }^{14}$ Medication adherence was calculated using proportion of days covered (PDC), which was calculated for all the OAD claims of each patient together and not separately for each OAD class, using the CMS 
cross-sectional design for PDC calculation. ${ }^{15}$ The outcome variable was dichotomized: patients with $\mathrm{PDC} \geq 0.8$ were categorized as "adherent," while patients with PDC $<0.8$ were "nonadherent." In addition to alignment with CMS calculations, use of PDC and the cutoff value of 0.8 to measure adherence is justified because of its highest predictive validity for clinically meaningful outcomes in diabetes patients. ${ }^{16,17}$

Predictor variables were calculated in the baseline year and included demographic characteristics, medication characteristics, and health care characteristics (Appendix A, available in online article). Medication characteristics included last filled class of OAD, total number of different classes of OADs that were refilled, total number of refills of OADS, days supply of OAD that was last refilled, last OAD duration, type of OAD most refilled, pill burden (defined as the total number of pills per days ${ }^{18}$ ), total number of therapeutic classes, average dosing frequency of OADs, and past adherence (see Appendix A for operational definitions). Health care characteristics included duel eligibility status, comorbidity burden (assessed using the Deyo adaptation of the Charlson Comorbidity Index ${ }^{19}$ ) and adjusting outpatient claims for overestimation of comorbidities, ${ }^{20}$ diabetes severity (assessed using the adapted Diabetes Complications Severity Index [DCSI] ${ }^{21}$, emergency room visits, type of physician most visited, number of physicians visited, and type of pharmacy.

In this study, the past adherence variable was calculated as a combination of 2 variables: adherence in baseline year and time of first prescription. Adherence in baseline year was calculated using PDC as previously discussed. The time of first prescription variable was divided into 3 categories: prescribed in the last half of baseline year, prescribed in the first half of baseline year, and prescribed before baseline year, since the prediction ability of PDC was associated with the time of OAD initiation. For example, if a patient initiated a medication in 2010 and his or her adherence was 0.9 in 2012, then the patient was more likely to be adherent in 2013 as well. However, if a patient initiated a medication on October 1, 2012, with 90 days of supply, the patient's PDC would be 1.00 , but we cannot be sure if the patient would continue to be adherent. In short, the time from first prescription variable was introduced to avoid overestimation of PDC for patients who started OADs in the last few months of the baseline year.

The past adherence variable had 3 categories: category 1 (good), initiation time before baseline year and $\mathrm{PDC} \geq 0.9$; category 2 (poor); initiation time before baseline year and $\operatorname{PDC}<0.4$, or initiation time in the first half of baseline year and $\mathrm{PDC}<0.6$, or initiation time in the second half of baseline year and $\mathrm{PDC}<0.8$; and category 3 (average), the rest of the patients. The cutoff for the categories were selected so as to have stronger positive (for category 1) and negative (for category 2) correlation of past adherence with future adherence. The rationale was that patients who initiated before the baseline year and had high adherence in the baseline year were most likely to be adherent in the follow-up year. Patients who initiated before the baseline year and had low adherence or patients who initiated in the baseline year and had mediocre adherence were most likely to be nonadherent in the follow-up year. It would be difficult to predict nonadherence for other patients.

Although cost of prescription medication and out-of-pocket cost were found to be important predictors in the literature, they were not used in this study, since cost is highly variable and would require yearly adjustment, thus complicating the algorithm for pragmatic use. Predictor variables with the majority $(\geq 95 \%$ ) of patients in 1 of the 2 categories were not used in the prediction model. The model included whether brand or generic OADs were used (majority were on generic medications), dosing frequency of OAD (majority were on twice daily), and type of physician visited (majority visited primary physician).

\section{Development and Validation of Predictive Model}

All the relevant variables identified from the literature were included for model development to avoid predictor selection bias associated with forward/backward/stepwise selection. ${ }^{22}$ The predictor variables were identified to cause multicollenearity problems if absolute value of the correlation coefficient was $>0.7$, condition index was $>30$, and variance inflation factor (VIF) was $>10 .{ }^{23}$ All the independent variables were tested for correlation using Spearman correlation statistics. If the correlation coefficient between any 2 predictor variables was $>0.7$, then the variable with comparatively greater correlation to nonadherence was included in the final model.

The predictive model was developed by bootstrapping the entire sample (with replacement) and conducting multiple logistic regression analysis in each of the 200 bootstrapped samples. Variables that were statistically significant $(P<0.05)$ in $\geq 50 \%$ of the logistic models constituted the final predictive model. The final predictive model was validated on the original sample, as well as using the 10 -fold cross-validation method, and evaluated using discrimination (C-index) and calibration statistics (Hosmer-Lemeshow test).

\section{Development and Evaluation of Prediction Tool}

The average of the median beta estimates obtained from the 200 logistic models was calculated for all variables to obtain unbiased estimates. ${ }^{24}$ The beta ( $\beta$ ) estimates of the statistically significant variables were then summarized for each patient using the formula $\mathrm{L}=\beta_{1} x_{1}+\beta_{2} x_{2}+\beta_{4} x_{4}+\beta_{n} x_{n}$, where $\beta_{1}, \beta_{2}, \ldots \beta_{n}$ were the median beta estimates of statistically significant variables and $x_{1}, x_{2}, \ldots x_{n}$ were the statistically significant variables. The final risk score for each patient was then obtained using exponential ${ }_{C^{L}}$ conversion of the summary score (L), using the formula $\left(\frac{e^{L}}{1+e^{L}}\right) \times 100.25$

A cutoff point was calculated at a point where sensitivity, specificity, negative prediction value (NPV), positive prediction value (PPV), and total accuracy were optimal. ${ }^{26}$ Patients with 
scores below the cutoff were categorized as low-risk patients, and those with score above the cutoff were categorized as highrisk patients.

The predictive tool was tested for sensitivity, specificity, positive prediction value (PPV), and negative prediction value (NPV) ${ }^{26}$ The predictive ability of the tool was compared with that of past PDCs using net reclassification improvement (NRI) and integrated discrimination improvement (IDI) ${ }^{27}$ The operational definitions of the parameters used to test RxAPT-D performance are provided in Appendix B (available in the online article).

Descriptive statistics of the patients were conducted for the categorized predictor variables using the chi-square $\left(\chi^{2}\right)$ test. All analyses were conducted using SAS, version 9.3 (SAS Institute, Cary, NC).

\section{Results}

A total of 7,028 patients were included for RxAPT-D development and validation. Mean age of patients was 74.78 years; females were in slight majority (56.3\%; Table 1). The majority of included patients had moderate diabetes severity as defined by DCSI scores of 1-3 (54.8\%); were on monotherapy (63.9\%, mostly metformin); and were adherent to OADs in the baseline year (59.6\%).

Variables that lacked adequate patient distribution across each variable category were not included in the final analysis. These variables were type of OAD refilled, dosing frequency of $\mathrm{OAD}$, and type of physician most visited. Two predictor variables-total number of therapeutic classes and class of OAD last refilled-were dropped from the prediction model because of multicollinearity. In the predictive model, VIF values of all variables were less than 10 , and the condition index value was $<30$, which satisfied the criteria for absence of multicollinearity. Table 2 presents multicollinearity statistics (VIF and tolerance) for variables included in the logistic regression model for algorithm development.

Seven predictor variables, statistically significant $(P>0.05)$ in $\geq 50 \%$ of the 200 bootstrapped prediction models, were identified: age, total number of OAD refills, total number of different classes of OADS that were refilled, days supply of OAD that was last refilled, pill burden, last OAD duration, and past adherence (Table 3). When the final logistic model was used in the original sample, c-index value was 0.75 , and HosmerLemeshow goodness-of-fit was $P>0.05$. The area under the curve (AUC) statistics for 10-fold cross-validation was above 0.7; AUC was 0.728 for the training sample and 0.727 for the validation sample, indicating good internal validity.

The mean RxAPT-D score in the total sample was 65.91, and it ranged from 33 to 91 (Figure 2). The increase in risk score was directly proportional to the increase in nonadherent patients. Using the cutoff of $0.70,72.9 \%$ of the nonadherent patients were correctly classified as high-risk patients, and $37.2 \%$ of the adherent patients were misclassified as high risk.

\section{TABLE 1 Descriptive Characteristics of the} Study Population

\begin{tabular}{|c|c|c|}
\hline Variables & $\begin{array}{l}\text { Frequency }{ }^{\mathrm{a}} \\
(\mathrm{N}=7,028)\end{array}$ & Percentage \\
\hline Age, mean (SD) & 74.78 & 6.1 \\
\hline \multicolumn{3}{|l|}{ Age (years) } \\
\hline $65-74$ & 3,971 & 56.5 \\
\hline $75-84$ & 2,614 & 37.2 \\
\hline$\geq 85$ & 443 & 6.4 \\
\hline \multicolumn{3}{|l|}{ Sex } \\
\hline Males & 3,071 & 43.7 \\
\hline Females & 3,957 & 56.3 \\
\hline \multicolumn{3}{|l|}{ Emergency room visit } \\
\hline Absent & 5,749 & 81.8 \\
\hline Present & 1,279 & 18.2 \\
\hline \multicolumn{3}{|l|}{ Diabetes severity } \\
\hline Mild (DCSI =0) & 1,525 & 21.7 \\
\hline Moderate (DCSI = 1-3) & 3,851 & 54.8 \\
\hline Severe $(\mathrm{DCSI} \geq 3)$ & 1,652 & 23.5 \\
\hline \multicolumn{3}{|l|}{ Comorbidity index } \\
\hline Absent $(\mathrm{CCI}=0)$ & 4,154 & 59.1 \\
\hline Present $(\mathrm{CCI}>0)$ & 2,874 & 40.9 \\
\hline \multicolumn{3}{|l|}{ OAD therapy } \\
\hline Monotherapy only & 4,491 & 63.9 \\
\hline Combination therapy only & 2,158 & 30.7 \\
\hline Mono and combination therapy & 380 & 5.4 \\
\hline \multicolumn{3}{|c|}{ Last refill covered until end of baseline year? } \\
\hline No & 1,687 & 24.0 \\
\hline Yes & 5,341 & 76.0 \\
\hline \multicolumn{3}{|l|}{ Type of pharmacy } \\
\hline Independent & 977 & 13.9 \\
\hline Chain & 6,051 & 86.1 \\
\hline \multicolumn{3}{|l|}{ Frequency of OAD refills } \\
\hline $0-4$ & 2,411 & 34.3 \\
\hline $5-8$ & 1,869 & 26.6 \\
\hline$>8$ & 2,748 & 39.1 \\
\hline \multicolumn{3}{|l|}{ Days supply of last refill } \\
\hline 30 & 3,591 & 51.1 \\
\hline 45 & 134 & 1.9 \\
\hline 60 & 3,303 & 47.0 \\
\hline \multicolumn{3}{|l|}{ Dual eligibility } \\
\hline Absent & 5,236 & 74.5 \\
\hline Present & 1,799 & 25.6 \\
\hline \multicolumn{3}{|l|}{ Baseline adherence } \\
\hline Adherent (PDC $\geq 0.8$ ) & 4,189 & 59.6 \\
\hline Nonadherent $(\mathrm{PDC}<0.8)$ & 2,839 & 40.4 \\
\hline Baseline PDC, mean (SD) & 0.8 & 0.2 \\
\hline \multicolumn{3}{|c|}{$\begin{array}{l}\text { aAll statistics are in terms of frequency and percentage unless otherwise specified } \\
\text { for individual variables. } \\
C C I=\text { Charlson Comorbidity Index; DCSI = Diabetes Complications Severity Index } \\
O A D=\text { oral antidiabetic drug; PDC = proportion of days covered; SD=standard } \\
\text { deviation. }\end{array}$} \\
\hline
\end{tabular}

The sensitivity statistics were optimum for not only the entire sample but also for randomly chosen subsamples (Table 4). RxAPT-D had better prediction ability compared with the 


\begin{tabular}{l|c|c}
\hline \multicolumn{1}{c}{ TABLE 2 } & $\begin{array}{c}\text { Multicollinearity Statistics of the Final } \\
\text { Predictors Variables Included for } \\
\text { Algorithm Development }\end{array}$ \\
\hline Variable & VIF & Tolerance \\
\hline Age & 4.4 & 0.23 \\
\hline Sex & 1.0 & 0.97 \\
\hline Total number of therapeutic classes & 1.3 & 0.84 \\
\hline Total OAD refills & 2.6 & 0.65 \\
\hline OAD days supply & 1.6 & 0.97 \\
\hline Last OAD duration & 1.3 & 0.77 \\
\hline Pill burden & 3.0 & 0.50 \\
\hline Dual eligibility status & 1.1 & 0.95 \\
\hline Comorbidity burden & 1.3 & 0.78 \\
\hline Diabetes severity & 2.0 & 0.57 \\
\hline ER visits & 1.1 & 0.91 \\
\hline Number of physicians visited & 2.9 & 0.88 \\
\hline Type of pharmacy & 1.1 & 0.95 \\
\hline Past adherence & 1.4 & 0.84 \\
\hline aThe highest VIF and lowest tolerance values for each variable are reported. \\
CCI=Charlson Comorbidity Index; DCSI=Diabetes Complications Severity Index; \\
ER=emergency room; OAD=oral antidiabetic drug; VIF=variance inflation factor. \\
\hline
\end{tabular}

prediction ability of baseline PDC; relative IDI was 2.09, and user-defined NRI was 0.16 with $24 \%$ events correctly reclassified.

\section{Discussion}

The predictive model that was developed to identify nonadherent patients consisted of 7 significant predictors: age, total number of OAD refills, total number of different classes of OADS that were refilled, days supply of OAD that was last refilled, pill burden, last OAD duration, and past adherence. The predictive model had good validity, and RxAPT-D, the predictive tool developed using the significant variables, demonstrated adequate sensitivity and specificity. All patients included in the study were enrolled in MA-PD by CignaHealthSpring and resided in the southeastern part of Texas. In 2012, the West South Central region of the United States, which includes Texas, was reported to have the lowest likelihood of adherent beneficiaries in the Medicare population. ${ }^{28}$ The proportion of patients with nonadherence (PDC $<0.8)$ to OADs in the study sample was around $40 \%$, which is higher than the CMS-reported national average (25\% in 2012 and 23\% in 2013) among MA-PD patients. ${ }^{4}$ The high rate of nonadherence to OADs in this population highlights the need for innovative strategies to identify nonadherent patients and justifies our efforts in that direction.

The association of increased nonadherence with old age (85+ years), ${ }^{29-31}$ lower number of refills, ${ }^{32}$ lower days supply, ${ }^{31,33}$ and increased pill burden ${ }^{34-37}$ was consistent with the literature. The past adherence variable was developed specifically for the purpose of this study and calculated from predictor variables described in the literature. The most
TABLE 3 Logistic Regression Model for Prediction of Nonadherence in 2013

\begin{tabular}{l|c|c} 
Variable & $\begin{array}{c}\text { Average Median } \\
\text { Beta Estimate } \\
\text { Value }^{\mathrm{a}}\end{array}$ & Standard Deviation \\
\hline Age (years) & 0.25 & 0.12 \\
\hline$\geq 85$ & 0.08 & 0.06 \\
\hline $75-84$ & Reference & \\
\hline $65-74$ & -0.01 & 0.03 \\
\hline Sex & Reference & \\
\hline Females & 1.03 & 0.05 \\
\hline Males & -0.24 & 0.05 \\
\hline Total number of different classes of OADS that were refilled \\
\hline 1 & Reference & \\
\hline 2 & \multicolumn{2}{|l}{} \\
\hline$\geq 3$ & 0.15 & 0.05 \\
\hline Total number OAD refills & 0.10 & 0.04 \\
\hline $0-4$ & Reference \\
\hline $5-8$ &
\end{tabular}

Days supply of OAD that was last refilled

\begin{tabular}{l|c|c}
\hline $30-59$ & 0.28 & 0.07 \\
\hline $60-89$ & -0.00 & 0.13 \\
\hline$\geq 90$ & Reference & \\
\hline
\end{tabular}

\begin{tabular}{l|c|c}
\hline Duration of last OAD refilled & \multicolumn{2}{l}{} \\
\hline Absent & 0.29 & 0.07 \\
\hline Present & Reference & \\
\hline
\end{tabular}

\begin{tabular}{l|l|l}
\hline Present & Reference & \\
\hline Pill burden &
\end{tabular}

\begin{tabular}{l|c|c}
\hline Pill burden & \multicolumn{2}{l}{} \\
\hline$\leq 5$ & 0.09 & 0.07 \\
\hline 5 to $\leq 10$ & -0.12 & 0.04 \\
\hline$>10$ to $\leq 20$ & -0.01 & 0.05 \\
\hline$>20$ & Reference & \\
\hline Dual eligibility & &
\end{tabular}

\begin{tabular}{l|c|c}
\hline Dual eligibility & \multicolumn{2}{l}{} \\
\hline Absent & 0.01 & 0.03 \\
\hline Present & Reference &
\end{tabular}

\begin{tabular}{l|c|c}
\hline Present & Reference & \\
\hline Comorbidity burden & \\
\hline
\end{tabular}

\begin{tabular}{l|c|c}
\hline $\mathrm{CCI}>0$ & 0.03 & 0.06 \\
\hline $\mathrm{CCI}=0$ & Reference & \\
\hline
\end{tabular}

\begin{tabular}{l|c|c}
\hline Diabetes severity & \multicolumn{2}{l}{} \\
\hline Mild (DCSI $=0)$ & 0.02 & 0.05 \\
\hline Moderate $(\mathrm{DCSI}=1-3)$ & 0.00 & 0.03 \\
\hline Severe $(\mathrm{DCSI} \geq 3)$ & Reference & \\
\hline ER visits
\end{tabular}

\begin{tabular}{l|c|c}
\hline \multicolumn{2}{|c}{ Reference } & \\
\hline ER visits & -0.05 & 0.04 \\
\hline Absent & Refin
\end{tabular}

\begin{tabular}{l|c|c} 
Absent & -0.05 & 0.04 \\
\hline Present & Reference & \\
\hline Number of different types of physicians visited &
\end{tabular}

\begin{tabular}{l|c|c}
\hline Number of different types of physicians visited & \\
\hline 0 & 0.12 & 0.21 \\
\hline 1 & -0.05 & 0.07 \\
\hline 2 & 0.06 & 0.08 \\
\hline 3 & Reference & \\
\hline
\end{tabular}

\begin{tabular}{ll} 
Type of pharmacy & \\
\hline
\end{tabular}

\begin{tabular}{l|c|c}
\hline Independent & 0.06 & 0.04 \\
\hline Chain & Reference & \\
\hline Past adherence & -0.31 & 0.05 \\
\hline Good & 0.31 & 0.08 \\
\hline Poor & Reference & \\
\hline Average &
\end{tabular}

avariable categories that are statistically significant $(P<0.05)$ in $\geq 50 \%$ of the bootstrapped logistic models are indicated in bold. These variables were used to calculate the RXAPT-D risk score.

$C C I=$ Charlson Comorbidity Index; DCSI = Diabetes Complications Severity Index; $E R=$ emergency room; $O A D=$ oral antidiabetic drug; $R \times A P T-D=$ Prescription

Medication Adherence Prediction Tool for Diabetes Medications. 


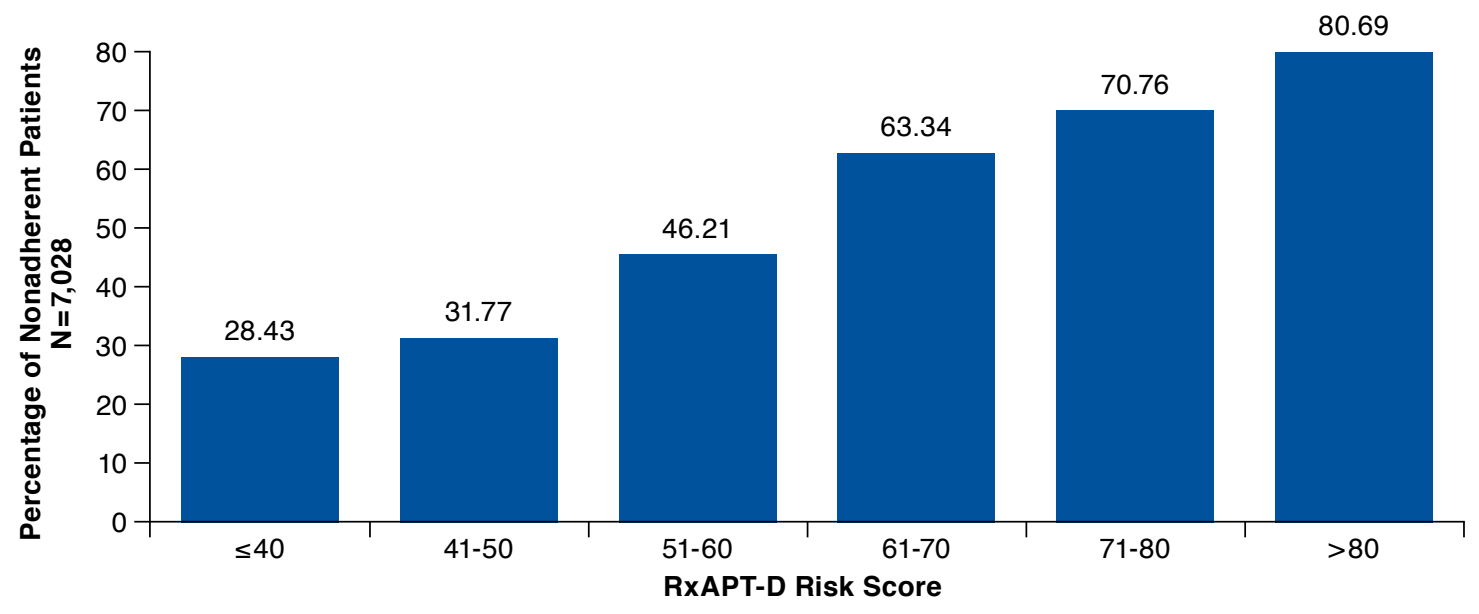

RxAPT-D=Prescription Medication Adherence Prediction Tool for Diabetes Medications.

significant predictor of nonadherence to OADs was the total number of OAD classes that were prescribed in the baseline year. No other studies have tested this association. Since a patient needs to visit a physician for drug switching, it may be postulated that decreased nonadherence in these patients is a result of higher physician visits because of increased involvement in health. Considering the high predictive power of this variable with future nonadherence, it would be interesting to investigate this relationship further.

The last OAD duration variable was assessed in this study to identify patients who were exhibiting high adherence behavior until the end of the baseline year. Patients with an OAD refill that provided medication coverage up to the end of the baseline year were more likely to be adherent in the next year. This assessment seems to hinge on the fact that behavior of human beings is constantly changing so the most recent behavior is a strong predictor of preceding behavior, compared with a behavior in the distant past.

The past adherence variable did not consist solely of past PDC values, but a combination of past PDC values and if the OAD was initiated the previous year (if yes, which half of the year). Past adherence has been used in the literature to predict future adherence, ${ }^{32}$ but this is the first study where the time frame of past adherence is also taken into consideration. The time frame of past PDC calculations was incorporated to account for 2 factors: (1) if a patient's adherence level has now become a part of the patient's habit and (2) the period of availability of past adherence information. Habit formed through repeated behavior of medication use is an important predictor of future medication use. ${ }^{38}$ Based on habit theory, medication adherence in the long term is theorized to occur when patients repeat or practice a medication-taking routine long enough to maintain the behavior. ${ }^{39}$ Based on this definition, patients with low (high) PDC values calculated over a longer time could be assumed as habitual nonadherents (adherents), while the adherence of patients with limited habitual history may be difficult to predict. This, along with the fact that the predictive ability of past adherence to predict future adherence increases with the increase in the length of data available about past adherence, ${ }^{40}$ helped us segregate patients based on how accurately their future nonadherence risk can be predicted.

The study results were as hypothesized-patients with low (high) past PDC and longer medication dispense history could be accurately predicted as high (low) risk patients, compared with patients with limited medication dispense history in the past. Consideration of duration of past medication dispense history would not be required if all patients had a constant baseline PDC information of 12 months (i.e., initiated an OAD before or at the beginning of the baseline year). However, this would eliminate many patients on OADs who would be eligible for star-rating calculation.

The results of RxAPT-D performance statistics (sensitivity, specificity, PPV, and NPV) should be interpreted with the understanding that the values will vary based on the cutoff point chosen. Ideally, one would want to have a test that is highly sensitive and highly specific, but this is not always possible. When the cutoff point between low risk and high risk is changed to increase either sensitivity or specificity, there is usually a concomitant decrease in the other. The cutoff point may therefore be varied to increase sensitivity (e.g., when important not to miss diagnosis) or specificity (e.g., when false positive diagnosis can be lethal), with concomitant decrease in the other, according to what is the purpose of the test. ${ }^{41}$ 


\section{TABLE 4 Performance Statistics of RXAPT-D}

\begin{tabular}{l|c|c|c}
\hline Performance Statistics & Entire Data & 50\% Data & 25\% Data \\
\hline Sensitivity & 0.73 & 0.73 & 0.76 \\
\hline Specificity & 0.63 & 0.61 & 0.62 \\
\hline Positive prediction value & 0.74 & 0.73 & 0.75 \\
\hline Negative prediction value & 0.62 & 0.61 & 0.62 \\
\hline
\end{tabular}

RxAPT-D = Prescription Medication Adherence Prediction Tool for Diabetes Medications.

In this study, we demonstrated that, compared with the past PDC measure, RxAPT-D more accurately classified patients with high and low risk for nonadherence. Past adherence is an easy-to-use tool compared with RxAPT-D. However, considering that RxAPT-D gives 2 times the accurate classification, implementation of RxAPT-D may provide additional benefit for nonadherence prediction.

\section{Limitiations}

The results of this study should be interpreted in light of various limitations. The algorithm suffers from retrospective claims data limitations such as coding errors and incomplete claims information. Use of a dichotomous adherence measure may decrease sensitivity. However, the decision to use retrospective data and a dichotomous measurement of adherence was aligned with CMS methods of measuring adherence to OADs for star ratings calculations, thus, increasing its applicability for MCOs. It is possible that the Medicare diabetes patients in this study have characteristics that differ from those in other settings, which could affect the generalizability of our findings.

While RxAPT-D was tested to identify patients at high risk for nonadherence, we were unable to test if these patients could improve adherence or whether targeting the identified patients would improve star ratings. The group of potential predictors that we studied was broad but not all inclusive. These predictors included variables either not available or routinely captured in the claims data, such as medication preference, perceived benefit of medication, race, socioeconomic status, and ZIP codes. Also, patients enrolled in medication adherence programs could not be identified from the data. One of the significant variables, past adherence, was created for the purpose of increasing the predictive ability of the model and is not validated. Some of the nonadherence calculated from the claims data may be because of physician recommendation for reasons such as adverse events and may falsely provide lower adherence scores.

\section{Implications and Future Research}

In spite of these limitations, a prediction tool with the ability to identify nonadherent patients is another step towards ongoing efforts to increase medication adherence by MCOs. In practice, an automated system that uses patient demographic and pharmacy claims files could identify the vast majority of patients at high risk of nonadherence to OADs. By running the 7-variable model on a prescription-filling dataset at the end of a calendar year, subjects would be identified as soon as they met the model's criteria for high risk, which can be targeted for personalized adherence interventions. Of the 7 significant variables, 1 variable is from member demographics, and 6 variables are from pharmacy claims. This makes the algorithm highly feasible and applicable, since patient demographic information is available for all patients, and pharmacy claims are up to date and, for the most part, cleaner (less error and missing data) and easier to work with than other administrative health care claims databases (i.e., medical and laboratory claims). ${ }^{42}$

Future studies testing the predictive algorithm for external and temporal validity are required. An important next step towards external validation is to test the predictive ability of the instrument on OAD users beyond the Cigna MA-PD Texas population, by using data from other MCOs and from other parts of the country. Studies experimenting with other approaches for predictive modeling are needed. Models based on artificial intelligence using neural networks are being used in financial, legal, and actuarial sectors, as well as health care payers and disease management. Subjecting the dataset to model-building methods such as these may help identify important predictors that are otherwise overlooked. This work can be extended to develop adherence prediction tools for other medications used in the CMS star rating measurements, such as statins and antihypertensives.

\section{Conclusions}

The prediction statistics identified the RxAPT-D as an effective tool to predict patients at high risk for nonadherence to OADs, with adequate sensitivity statistics, and as a better predictor of nonadherence to OADs compared with past PDC. Future studies on external validation are required.

\section{Authors}

SHIVANI K. MHATRE, PhD; MARC L. FLEMING, PhD, MPH, RPh; E. JAMES ESSIEN, MD, DrPH; and SUJIT S. SANSGIRY, PhD, University of Houston College of Pharmacy, Houston, Texas. OMAR SERNA, PharmD, Cigna-HealthSpring, Houston, Texas. SHUBHADA SANSGIRY, PhD, Houston VA Health Services Research and Development, Center for Innovations in Quality, Effectiveness and Safety, Michael E. DeBakey VA Medical Center; VA South Central Mental Illness Research, Education and Clinical Center; and Department of Medicine, Baylor College of Medicine, Houston, Texas.

AUTHOR CORRESPONDENCE: Sujit S. Sansgiry, PhD, Professor, Department of Pharmaceutical Health Outcomes and Policy, College of Pharmacy, University of Houston Texas Medical Center, 1441 Moursund St., Houston TX 77030. Tel.: 832.842.8392;

Fax: 832.842.8383; E-mail: sansgiry@central.uh.edu. 


\section{DISCLOSURES}

This study received unrestricted partial funding from the Pharmaceutical Research and Manufacturers of America (PhRMA) Foundation Adherence Research Starter Award. Serna is employed by Cigna-HealthSpring. Mhatre is now employed with Genentech. The authors report no other potential conflicts of interest.

The material in this study is based on work supported (or supported in part) by the Department of Veterans Affairs, Veterans Health Administration, Office of Research and Development, and the Center for Innovations in Quality, Effectiveness and Safety (CIN 13-413). The views expressed in this article are those of the authors and do not necessarily reflect the position or policy of the Department of Veterans Affairs or the U.S. government.

The abstract for this article was presented at the Academy of Managed Care Pharmacy's 28th Annual Meeting \& Expo, April 2016, San Francisco, California, with the title "Development and Validation of a Tool to Predict Nonadherence to Oral Antidiabetic Drugs in Medicare Beneficiaries."

Study concept and design were primarily contributed by Sujit Sansgiry and Mhatre, with assistance from the other authors. Mhatre, Serna, and Sujit Sansgiry took the lead in data collection, assisted by the other authors, and data interpretation was performed by Mhatre, Shubhada Sansgiry, and Essien, assisted by the other authors. The manuscript was written by Mhatre and Fleming, assisted by the other authors, and revised primarily by Mhatre, along with Sujit Sansgiry and assisted by the other authors.

\section{REFERENCES}

1. American Diabetes Association. Economic costs of diabetes in the U.S. in 2012. Diabetes Care. 2013;36(4):1033-46

2. Herman WH. The economic costs of diabetes: is it time for a new treatment paradigm? Diabetes Care. 2013;36(4):775-76.

3. American Diabetes Association. Standards of medical care in diabetes2014. Diabetes Care. 2014;37(Suppl 1):S14-S80.

4. Centers for Medicare \& Medicaid Services. CMS Medicare health \& drug plan quality and performance ratings 2015 Part C \& Part D technical notes. In 2015 Part C \& D Medicare star ratings data (v4 16 2015). Available at: http://www.cms.gov/medicare/prescription-drug-coverage/prescriptiondrugcovgenin/performancedata.html. Accessed September 20, 2016.

5. Sokol MC, McGuigan KA, Verbrugge RR, Epstein RS. Impact of medication adherence on hospitalization risk and healthcare cost. Med Care. 2005; 43(6):521-30

6. Balkrishnan R, Rajagopalan R, Camacho FT, Huston SA, Murray FT, Anderson RT. Predictors of medication adherence and associated health care costs in an older population with type 2 diabetes mellitus: a longitudinal cohort study. Clin Ther. 2003;25(11):2958-71.

7. Roebuck MC. Medical cost offsets from prescription drug utilization among Medicare beneficiaries. J Manag Care Spec Pharm. 2014;20(10):994-95. Available at: http://www.jmcp.org/doi/10.18553/jmcp.2014.20.10.994.

8. Weiss HB, Sauber-Schatz EK, Cook LJ. The epidemiology of pregnancyassociated emergency department injury visits and their impact on birth outcomes. Accid Anal Prev. 2008;40(3):1088-95.

9. Farina K. Coverage of the Academy of Managed Care Pharmacy (AMCP) 24th annual meeting and expo. Am J Pharm Benefits. 2012;4(3):125-35.

10. Cumming RB, Knutson D, Cameron BA, Derrick B. A comparative analysis of claims-based methods of health risk assessment for commercial populations. Society of Actuaries. May 24, 2002. Available at: https://www. soa.org/Files/Research/Projects/2005-comp-analysis-methods-commercialpopulations.pdf. Accessed October 3, 2016

11. Winkelman R, Mehmud S. A comparative analysis of claims-based tools for health risk assessment. Society of Actuaries. April 20, 2007. Available at: https://www.soa.org/research/research-projects/health/hlth-risk-assement. aspx. Accessed September 20, 2016
12. Hill-Taylor B, Sketris I, Hayden J, Byrne S, O'Sullivan D, Christie R. Application of the stopp/start criteria: a systematic review of the prevalence of potentially inappropriate prescribing in older adults, and evidence of clinical, humanistic and economic impact. J Clin Pharm Ther. 2013;38(5):360-72.

13. Yang Y, Thumula V, Pace PF, Banahan III BF, Wilkin NE, Lobb WB Predictors of medication nonadherence among patients with diabetes in Medicare Part D programs: a retrospective cohort study. Clin Ther. 2009;31(10):2178-88

14. Cramer JA, Roy A, Burrell A, et al. Medication compliance and persistence: terminology and definitions. Value Health. 2008;11(1):44-47.

15. Leslie RS. Estimating medication adherence using a patient-mix adjustment method. Paper presented at: Proceedings of the 2014 PharmaSUG; June 1-4, 2014, San Diego, CA. Available at: http://www.lexjansen.com/pharmasug/2014/HA/PharmaSUG-2014-HAl0.pdf. Accessed September 20, 2016.

16. Karve S, Cleves MA, Helm M, Hudson TJ, West DS, Martin BC. An empirical basis for standardizing adherence measures derived from administrative claims data among diabetic patients. Med Care. 2008;46(11):1125-33.

17. Karve S, Cleves MA, Helm M, Hudson TJ, West DS, Martin BC. Good and poor adherence: optimal cut-point for adherence measures using administrative claims data. Curr Med Res Opin. 2009;25(9):2303-10.

18. Chiu YW, Teitelbaum I, Misra M, de Leon EM, Adzize T, Mehrotra R. Pill burden, adherence, hyperphosphatemia, and quality of life in maintenance dialysis patients. Clin J Am Soc Nephrol. 2009;4(6):1089-96.

19. Deyo RA, Cherkin DC, Ciol MA. Adapting a clinical comorbidity index for use with ICD-9-CM administrative databases. J Clin Epidemiol. 1992;45(6):613-19.

20. Klabunde CN, Potosky AL, Legler JM, Warren JL. Development of a comorbidity index using physician claims data. J Clin Epidemiol. 2000;53(12):1258-67.

21. Chang HY, Weiner JP, Richards TM, Bleich SN, Segal JB. Validating the adapted diabetes complications severity index in claims data. Am J Manag Care. 2012;18(11):721-26

22. Harrell FE Jr. Regression Modeling Strategies: With Applications to Linear Models, Logistic Regression, and Survival Analysis. New York: Springer; 2001.

23. Dormann CF, Elith J, Bacher S, et al. Collinearity: a review of methods to deal with it and a simulation study evaluating their performance. Ecography. 2013;36(1):27-46

24. Harrell F, Lee KL, Mark DB. Tutorial in biostatistics multivariable prognostic models: issues in developing models, evaluating assumptions and adequacy, and measuring and reducing errors. Stat Med. 1996;15:361-87.

25. Pugely AJ, Martin CT, Gao Y, Klocke NF, Callaghan JJ, Marsh JL. A risk calculator for short-term morbidity and mortality after hip fracture surgery. J Orthop Trauma. 2014;28(2):63-69.

26. Lambert J, Lipkovich I. A macro for getting more out of your ROC curve. Poster presented at: SAS Global Forum 2008; March 16-18, 2008; San Antonio, TX. Available at: http://www2.sas.com/proceedings/ forum2008/231-2008.pdf. Accessed September 20, 2016.

27. Pencina MJ, D'Agostino RB, Vasan RS. Evaluating the added predictive ability of a new marker: from area under the ROC curve to reclassification and beyond. Stat Med. 2008;27(2):157-72.

28. Couto JE, Panchal JM, Lal LS, et al. Geographic variation in medication adherence in commercial and Medicare Part D populations. J Manag Care Spec Pharm. 2014;20(8):834-42. Available at: http://www.jmcp.org/ doi/10.18553/jmcp.2014.20.8.834.

29. Munro SA, Lewin SA, Smith HJ, Engel ME, Fretheim A, Volmink J. Patient adherence to tuberculosis treatment: a systematic review of qualitative research. PLoS Med. 2007;4(7):e238.

30. Ruddy K, Mayer E, Partridge A. Patient adherence and persistence with oral anticancer treatment. CA Cancer J Clin. 2009;59(1):56-66. 
31. Schmittdiel JA, Nichols GA, Dyer W, Steiner JF, Karter AJ, Raebel MA. Health care system-level factors associated with performance on medicare star adherence metrics in a large, integrated delivery system. Med Care. 2015;53(4):332-37.

32. Kardas P, Lewek P, Matyjaszczyk M. Determinants of patient adherence: a review of systematic reviews. Front Pharmacol. 2013;4:91.

33. Shrank WH, Stedman M, Ettner SL, et al. Patient, physician, pharmacy, and pharmacy benefit design factors related to generic medication use. J Gen Intern Med. 2007;22(9):1298-304.

34. Mukhtar O, Weinman J, Jackson SH. Intentional non-adherence to medications by older adults. Drugs \& Aging. 2014;31(3):149-57.

35. Corsonello A, Pedone C, Lattanzio F, et al. Regimen complexity and medication nonadherence in elderly patients. Ther Clin Risk Manag. 2009;5(1):209-16.

36. de Vries ST, Keers JC, Visser R, et al. Medication beliefs, treatment complexity, and non-adherence to different drug classes in patients with type 2 diabetes. J Psychosom Res. 2014;76(2):134-38.
37. Ingersoll KS, Cohen J. The impact of medication regimen factors on adherence to chronic treatment: a review of literature. J Behav Med. 2008;31(3):213-24.

38. Molfenter TD, Bhattacharya A, Gustafson DH. The roles of past behavior and health beliefs in predicting medication adherence to a statin regimen. Patient Prefer Adherence. 2012;6:643-51.

39. Phillips AL, Leventhal H, Leventhal EA. Assessing theoretical predictors of long-term medication adherence: patients' treatment-related beliefs, experiential feedback and habit development. Health (London). 2013;28(10):1135-51.

40. Zimolzak AJ, Spettell CM, Fernandes J, et al. Early detection of poor adherers to statins: applying individualized surveillance to pay for performance. PLoS One. 2013;8(11):e79611.

41. Akobeng AK. Understanding diagnostic tests 3: receiver operating characteristic curves. Acta Paediatr. 2007;96(5):644-47.

42. Leslie RS, Gwadry-Sridhar F, Thiebaud P, Patel BV. Calculating medication compliance, adherence and persistence in administrative pharmacy claims databases. Pharma Prog. 2008;1(1):13-19. 


\section{APPENDIX A Calculation and Categorization of Predictor Variables for Model Development}

\begin{tabular}{|c|c|c|}
\hline Variable & Calculation (If Required) & Categories \\
\hline$\overline{\text { Age }}$ & Number of years from birth year to baseline year (2012) & $65-74$ years, $75-84$ years, $\geq 85$ years \\
\hline Sex & - & Male, female \\
\hline Last refilled class of OAD & Class of last OADs filled in 2012 & $\begin{array}{l}\text { Biguanides, sulphonyureas, thiazolidinedione, } \\
\text { DPP-4 inhibitors, meglitinides }\end{array}$ \\
\hline Different classes of OADs refilled & $\begin{array}{l}\text { Sum of different classes of OADs (biguanides, sulphony- } \\
\text { ureas, thiazolidinedione, DPP- } 4 \text { inhibitors, meglitinides) } \\
\text { refilled in } 2012\end{array}$ & $1,2, \geq 3$ \\
\hline Total refills of OADs & Sum of total number of claims for OADs in 2012 & $\leq 4,4$ to $\leq 8,>8$ \\
\hline Days supply of OADs & Days supply of last OAD refilled in 2012 & $30-59$ days, $60-89$ days, $\geq 90$ days \\
\hline Last OAD duration & $\begin{array}{l}\text { If days supply of last refilled OAD was enough to cover to } \\
\text { the end of baseline year (December 31, 2012), then yes; } \\
\text { otherwise no }\end{array}$ & Yes, no \\
\hline Type of OAD refilled & Most frequent type of OAD refilled in 2012 & Brand, generic \\
\hline Pill burden & $\begin{array}{l}\text { Average number of oral medications with solid dosage form } \\
\text { (tablets or capsules) in } 2012\end{array}$ & $\leq 5,>5$ to $\leq 10,>10$ to $\leq 20,>20$ \\
\hline Total number of therapeutic classes & $\begin{array}{l}\text { Calculated from therapeutic classes of medications (e.g., } \\
\text { antihistaminics, antihypertensives) }\end{array}$ & 1 to $\leq 5,6$ to $\leq 10,11$ to $\leq 15,>15$ \\
\hline Dosing frequency of $\mathrm{OAD}$ & $\begin{array}{l}\text { Average daily frequency calculated by dividing quantity } \\
\text { supplied for each refill by the days supply of refill }\end{array}$ & $\begin{array}{l}\text { Once a day, twice a day, thrice a day, and more } \\
\text { than thrice a day }\end{array}$ \\
\hline Dual eligibility status & $\begin{array}{l}\text { If patients had coverage by both Medicare and Medicaid, } \\
\text { then yes }\end{array}$ & Yes, no \\
\hline Comorbidity burden & $\begin{array}{l}\text { Using Deyo adaptation of CCI and Klabunde et al. }{ }^{26} \text { modi- } \\
\text { fication; followed by categorization of CCI score }\end{array}$ & $\mathrm{CCI}=0, \mathrm{CCI} \geq 1$ \\
\hline Diabetes severity & Using adapted DCSI & $0,1-3,>3$ \\
\hline ER visits & $\begin{array}{l}\text { Using ER claim showing primary diagnosis of any condi- } \\
\text { tion; only nonelective hospitalizations were considered }\end{array}$ & Yes, no \\
\hline Type of physician most visited & - & Primary care provider, specialty care provider \\
\hline Number of physicians visited & $\begin{array}{l}\text { Identified using physician identification associated with } \\
\text { physician visit claims }\end{array}$ & - \\
\hline Type of pharmacy & - & Chain, independent \\
\hline Past adherence & $\begin{array}{l}\text { Calculated by combining } 2 \text { variables: adherence in baseline } \\
\text { year and time of first prescription }\end{array}$ & Good, poor, unknown \\
\hline
\end{tabular}




\section{APPENDIX B Operational Definitions of RxAPT-D Performance Parameters}

Parameter

Operational Definition

Sensitivity

Ability of RxAPT-D to correctly identify patients at high risk for nonadherence

Specificity Ability of RxAPT-D to correctly identify patients at low risk for nonadherence

Positive prediction value Proportion of nonadherent patients among high-risk patients identified by RxAPT-D

Negative prediction value Proportion of adherent patients among low-risk patients identified by RxAPT-D

Net reclassification improvement Difference in ability of RxAPT-D to correctly reclassify high- and low-risk patients compared with past adherence measure

Integrated discrimination improvement

Difference in discrimination slopes of RxAPT-D and past adherence measure; discrimination slopes are the mean predicted probabilities of high- and low-risk groups

RxAPT-D = Prescription Medication Adherence Prediction Tool for Diabetes Medications. 